\title{
Cytoplasmic phospholipase A2 alpha overexpression in stromal cells is correlated with angiogenesis in human colorectal cancer
}

\author{
Dominique Wendum ${ }^{1,2}$, Eva Comperat ${ }^{1}$, Pierre-Yves Boëlle ${ }^{3}$, Rolland Parc ${ }^{4}$, Joëlle Masliah ${ }^{2}$, \\ Germain Trugnan $^{2}$ and Jean-François Fléjou ${ }^{1}$
}

${ }^{1}$ Department of Pathology, Hôpital Saint-Antoine (AP-HP), Paris, France; ${ }^{2}$ Unité INSERM U538; ${ }^{3} U 444$, Faculté de Médecine Saint-Antoine, Université Pierre et Marie Curie, Paris, France and ${ }^{4}$ Department of Digestive Surgery, Hôpital Saint-Antoine (AP-HP), Paris, France

\begin{abstract}
In colorectal cancer, cyclooxygenase-2 (COX-2) overexpression in stromal cells induces angiogenesis through EP2 prostaglandin E2 receptor signaling. Cytoplasmic phospholipase A2 (PLA2) alpha preferentially hydrolyses arachidonic acid, which is the limiting substrate for prostaglandin production, from membrane phospholipids. We therefore investigated a possible relationship between cytoplasmic PLA2 and COX-2 overexpression in stromal cells, angiogenesis and microsatellite instability in 48 human colorectal adenocarcinomas. Cytoplasmic PLA2 and COX-2 expression in stromal cells and vascular endothelial growth factor (VEGF) expression in tumor cells were evaluated by immunohistochemistry. Microvessel density was assessed in $10 \times 400$ fields after CD31 staining. Microsatellite instability was evaluated by PCR and immunohistochemistry. A total of 16 tumors had microsatellite instability. We found an overexpression of cytoplasmic PLA2 in superficial stromal cells. These cells corresponded to fibroblasts and myofibroblasts. There was an association between the number of cytoplasmic PLA2 and COX-2-expressing cells $(P=0.006)$. Cytoplasmic PLA2-positive stromal cells usually also expressed COX-2. A high number of cytoplasmic PLA2-positive stromal cells was correlated with a high microvessel density $(P=0.002)$, a strong VEGF $(P=0.01)$ and the absence of microsatellite instability $(P=0.001)$. The coordinate overexpression of cytoplasmic PLA2 and COX-2 in stromal cells could lead to an important prostaglandin production. These results suggest that cytoplasmic PLA2 overexpression in these cells regulates COX-induced angiogenesis probably by providing arachidonic acid, which is the limiting factor for prostaglandin production. The lower number of cytoplasmic PLA2-positive stromal cells in carcinomas with microsatellite instability could be related to their lower microvessel density and VEGF expression.
\end{abstract}

Modern Pathology (2005) 18, 212-220, advance online publication, 8 October 2004; doi:10.1038/modpathol.3800284

Keywords: colorectal cancer; cytoplasmic phospholipase A2; stroma; angiogenesis; cyclooxygenase-2

Cyclooxygenase-2 (COX-2) overexpression is directly involved in tumor development ${ }^{1}$ and particularly in colorectal tumor development. In animal models, COX-2 knockout or treatment with specific COX-2 inhibitors reduces intestinal tumor development. ${ }^{2-5}$ COX-2 tumor promotion probably involves different biological mechanisms, among them being the induction of tumor angiogenesis. ${ }^{6}$ Indeed, COX2 overexpression in colon cancer cells regulates angiogenesis in vitro and in vivo. ${ }^{7-9}$ In colon adenomas and carcinomas, COX-2 is overexpressed in

Correspondence: Dr D Wendum, MD, PhD, Department of Pathology, Hôpital Saint-Antoine, AP-HP, 184 rue du faubourg Saint Antoine, 75571 Paris Cedex 12.

E-mail: dominique.wendum@sat.ap-hop-paris.fr

Received 29 April 2004; revised and accepted 11 August 2004; published online 8 October 2004 tumor cells but also in interstitial stromal cells. ${ }^{10-14}$ COX-2 overexpression in interstitial stromal cells also induces tumor angiogenesis in several models of tumor development. ${ }^{15,16}$ In intestinal tumors, angiogenesis induced by COX-2 expressing interstitial stromal cells is mediated by prostaglandin E2 through EP2 prostaglandin E2 receptor signaling. ${ }^{17}$ However, prostaglandin production is also directly dependent on free arachidonic acid availability. Arachidonic acid is released from membrane phospholipids by phospholipase A2 (PLA2). Several types of PLA2 are expressed in human cells. Among them cytoplasmic PLA2, also known as type IV PLA2 alpha (PLA2 $\alpha$ ), preferentially hydrolyses $s n-2$ arachidonic acid that is the limiting substrate for COX-mediated prostaglandin production. ${ }^{18}$

Recently, we studied cytoplasmic PLA2 expression in human small bowel and colon 
adenocarcinomas and we noticed that some superficial stromal cells overexpressed this protein in these lesions. ${ }^{19}$ In this present work, we identified the stromal cells overexpressing cytoplasmic PLA2 in colorectal carcinomas. We also investigated whether cytoplasmic PLA2 expression in these stromal cells could be related to angiogenesis induction. We therefore studied the relationship between cytoplasmic PLA2 expression in stromal cells, COX-2 expression in these cells and angiogenesis in a large series of human colorectal carcinomas. As the presence of microsatellite instability is correlated with a lower angiogenesis in colon carcinomas, ${ }^{20-23}$ we also studied the relationship between cytoplasmic PLA2 expression in stromal cells and microsatellite instability in these tumors.

\section{Materials and methods}

\section{Samples}

A total of 65 colorectal carcinomas were studied. In all, 17 carcinomas had a totally ulcerated or necrotic surface; thus 48 samples could be evaluated with regard to cytoplasmic PLA2 and COX-2 expression in superficial stromal cells. They belonged to a wellcharacterized series of colorectal carcinomas selected from the pathology files of Saint-Antoine Hospital. ${ }^{24}$ All samples were surgical resections. Surgical specimens were fixed in $10 \%$ buffered formalin and embedded in paraffin. The stage was assessed according to the UICC cancer staging system. ${ }^{25}$

\section{Microsatellite Instability Assessment}

Microsatellite instability was studied on paraffinembedded tumor samples and on matching normal controls by polymerase chain reaction (PCR) and immunohistochemistry. Five to seven consecutive $20 \mu \mathrm{m}$ tissue sections were cut, and deparaffinized. DNA extraction was performed using QIAamp DNA Mini Kit (Qiagen, Courtaboeuf, France). DNA samples were amplified at six microsatellite loci. Five loci belonged to the reference panel (BAT25, BAT26, D2S123, D5S346, D17S250) and the sixth locus was an alternative locus (transforming growth factor $\beta$ receptor of type II (TGF $\beta$ RII)), according to the National Cancer Institute Workshop on microsatellite instability. ${ }^{26}$ Microsatellite instability in tumors was defined by two or more loci showing an electrophoretic shift. We also assessed microsatellite instability by immunohistochemical evaluation of hMLH1 and hMSH2 protein expression. This method was shown to be sensible and specific $^{27}$ (anti-human MLH1 monoclonal antibody, clone G168-728, 1/70, BD Pharmigen, and anti-human MSH2 monoclonal antibody, clone FE-11, 1/100, oncogene research products). Indeed, a loss of hMLH1 or hMSH2 protein expression was observed in all the carcinomas with microsatellite instability and in none of the others.

\section{Immunohistochemistry}

Consecutive $4 \mu \mathrm{m}$ tissue sections were cut from the same paraffin block that was used for microsatellite instability assessment. Immunostaining was performed using an avidin-biotin-peroxidase technique (Vectastain ABC Kit, Vector, Burlingame, CA, USA) for vascular endothelial growth factor (VEGF), COX-2 and cytoplasmic PLA2. A three-step indirect method was used for CD31. The following antibodies were used: (i) VEGF (A-20) rabbit polyclonal IgG (Santa Cruz Biotechnology, Santa Cruz, CA, USA) at a dilution of $1 / 100$, (ii) COX-2 mouse anti-human monoclonal antibody (Cayman Chemical, Ann Arbor, MI, USA) at a dilution of 1/600, (iii) cytoplasmic PLA2 mouse monoclonal antibody (sc454, Santa Cruz Biotechnology, Santa Cruz, CA, USA) at a dilution of 1/100 and (iv) CD31 mouse anti-human monoclonal antibody (M0823, DakoCytomation, Glostrup, Denmark) at a dilution of 1/30. Before immunostaining, endogenous peroxidase activity was inhibited with $0.1 \%$ hydrogen peroxide in methanol for $30 \mathrm{~min}$. Microwave antigen retrieval was performed for COX-2, cytoplasmic PLA2 and CD31 (750 W during $15 \mathrm{~min}$, then $150 \mathrm{~W}$ during $15 \mathrm{~min}$ ) in citrate buffer (0.01 mol/l, pH 6). Color development was achieved with 3-amino-9-ethyl-carbazole, and sections were finally counterstained with hematoxylin. Negative control slides were obtained by omitting the primary antibody, and by the use of irrelevant antibodies produced in the same animal. Irrelevant antibodies were matched for the antibody isotype in case of monoclonal antibodies. Negative controls for COX-2 and cytoplasmic PLA2 also included antibody preabsorption with the peptide used for immunization.

\section{Assessment of Stains}

Labeled ganglion cells or smooth muscle cells of blood vessels were used as internal control for VEGF staining. Superficial positive interstitial cells were used as internal control for COX-2 staining. A colon carcinoma overexpressing cytoplasmic PLA2, assessed by Western blot and immunohistochemistry, was used as a positive external positive control for cytoplasmic PLA2 staining.

VEGF scoring was performed by two authors independently (DW, JFF) using a semi quantitative score. $^{22,28}$ Scoring was performed in a blinded manner without knowledge of the microsatellite instability status, the microvessel density and the number of COX-2 or cytoplasmic PLA2 expressing superficial stromal cells in the tumors. Any tumor with a different final assessment was re-evaluated by a consensus review. 
Briefly, tumors were divided into four equal surface areas. VEGF staining in tumor cells was scored semiquantitatively as follows: 0, no staining or staining in less than $10 \%$ of the tumor cells, 1 , weak staining, 2 , moderate staining and 3 , strong staining. The final score (range from 0 to 12 ) was the sum of the four scores established for each subdivided area. When the final score was 0 or 1 we considered that there was no significant expression. A final score ranging from 2 to 5 defined a weak expression, a final score ranging from 6 to 9 defined a moderate expression and a final score ranging from 10 to 12 defined a strong expression

As stromal cells expressing cytoplasmic PLA2 were exclusively situated just below the surface epithelium, we evaluated the number of positive stromal cells in four random $\times 400$ fields below the luminal surface (total surface $0.39 \mathrm{~mm}^{2}$ ) in tumor areas without necrosis and distant from an ulcerated surface. Any stromal cell showing a cytoplasmic reactivity was counted. This count was performed without knowledge of the microsatellite instability status, VEGF expression and microvessel density in the tumor. COX-2-positive stromal cells were counted in the same fields on a consecutive tissue section.

\section{Quantification of Intratumoral Microvessel Density}

The vessel count was assessed by light microscopy on CD31-stained slides as previously described. ${ }^{22}$ In each case, the microvessels were counted in $10 \times 400$ fields $\left(0.97 \mathrm{~mm}^{2}\right)$. Vascularity was expressed as the total count of microvessels $/ \mathrm{mm}^{2}$.

\section{Immunofluorescence Detection and Scanning Laser Confocal Microscopy Analysis}

Double immunofluorescent stainings were performed on five samples. Tissue sections of paraffin-embedded tissue were dewaxed, rehydrated with TBS (tris buffer saline $\mathrm{pH}$ 7.6) and microwaved as previously described. Sections were simultaneously incubated with the anticytoplasmic PLA2 antibody (sc454, Santa Cruz Biotechnology, Santa Cruz, 1/20) and a rabbit anti-human polyclonal antibody: either an anti-COX-2 antibody (Cayman Chemical 1/70) or an antivimentin antibody (CBL 46, Cymbus Biotechnology, 1/15), or an anti-CD68 antibody (sc-9139, Santa Cruz, 1/150) or an antismooth muscle actin (LabVision Corporation, 1/ 150). Slides were incubated overnight at $4^{\circ} \mathrm{C}$ then washed three times for $5 \mathrm{~min}$ in TBS and successively incubated with fluorescein isothiocyanate (FITC)-conjugated donkey anti-mouse IgG antibody and Texas red isothiocyanate (TRITC)-conjugated donkey anti-rabbit IgG antibody (Jackson Laboratories) at a dilution of $1 / 100$ for $60 \mathrm{~min}$. Sections were then washed three times for $5 \mathrm{~min}$ in TBS and mounted in glycergel aqueous mounting medium
(Dako). Negative control slides were obtained as previously described for immunohistochemistry and were negative. In addition, by incubating the slides with the rabbit polyclonal antibodies alone no significant FITC signal was detected. By incubating the slides with the anticytoplasmic PLA2 antibody alone, no significant TRITC signal was detected.

Fluorescence was observed using a LEICA TCS spectral equipped with an inverted microscope and a 63/1.4 objective. A krypton/argon-mixed gas laser was used to generate two bands: $488 \mathrm{~nm}$ for FITC and $568 \mathrm{~nm}$ for TRITC. Both fluorochromes were excited and analyzed in sequential pass with no interference between the two channels. Image processing was performed using the on-line Scan Ware software.

\section{Statistical Analysis}

The association between categorical variables was tested by Fisher's exact test. The association between quantitative variables was tested with the Pearson correlation coefficient. For comparison of means, the $t$-test was used. All tests were two-sided, and a $P$-value less than 0.05 indicated statistical significance. The R software (http://cran.r-project. org) was used in all analyses.

\section{Results}

\section{Colon Carcinomas and Microsatellite Instability}

The average age of the patients was 63 years (range 33-89). A total of 30 carcinomas were located in the right colon and 18 in the left colon.

Of the 48 carcinomas, $16(33 \%)$ were stage I, 18 $(37 \%)$ were stage II, $11(23 \%)$ were stage III and three $(6 \%)$ were stage IV. Microsatellite instability was found in $16(33 \%)$ carcinomas.

Stage distribution was similar for the carcinomas without microsatellite instability compared to the carcinomas with microsatellite instability $(P=0.91)$.

\section{Cytoplasmic PLA2 Expressing Stromal Cells}

Cytoplasmic PLA2-positive stromal cells were exclusively situated just below the surface epithelium (Figure 1a). Cytoplasmic PLA2 immunostaining in stromal cells appeared cytoplasmic, with a granular pattern (Figure 1b). The median number of superficial stromal cells expressing cytoplasmic PLA2 in carcinomas was $62.8 / \mathrm{mm}^{2}$ (Table 1 ). There was a strong positive correlation between the number of superficial stromal cells expressing cytoplasmic PLA2 and the number of superficial stromal cells expressing COX-2 $(P=0.006)$. There were less numerous cytoplasmic PLA2-positive superficial stromal cells than COX-2-positive superficial stromal cells except in six cases. 

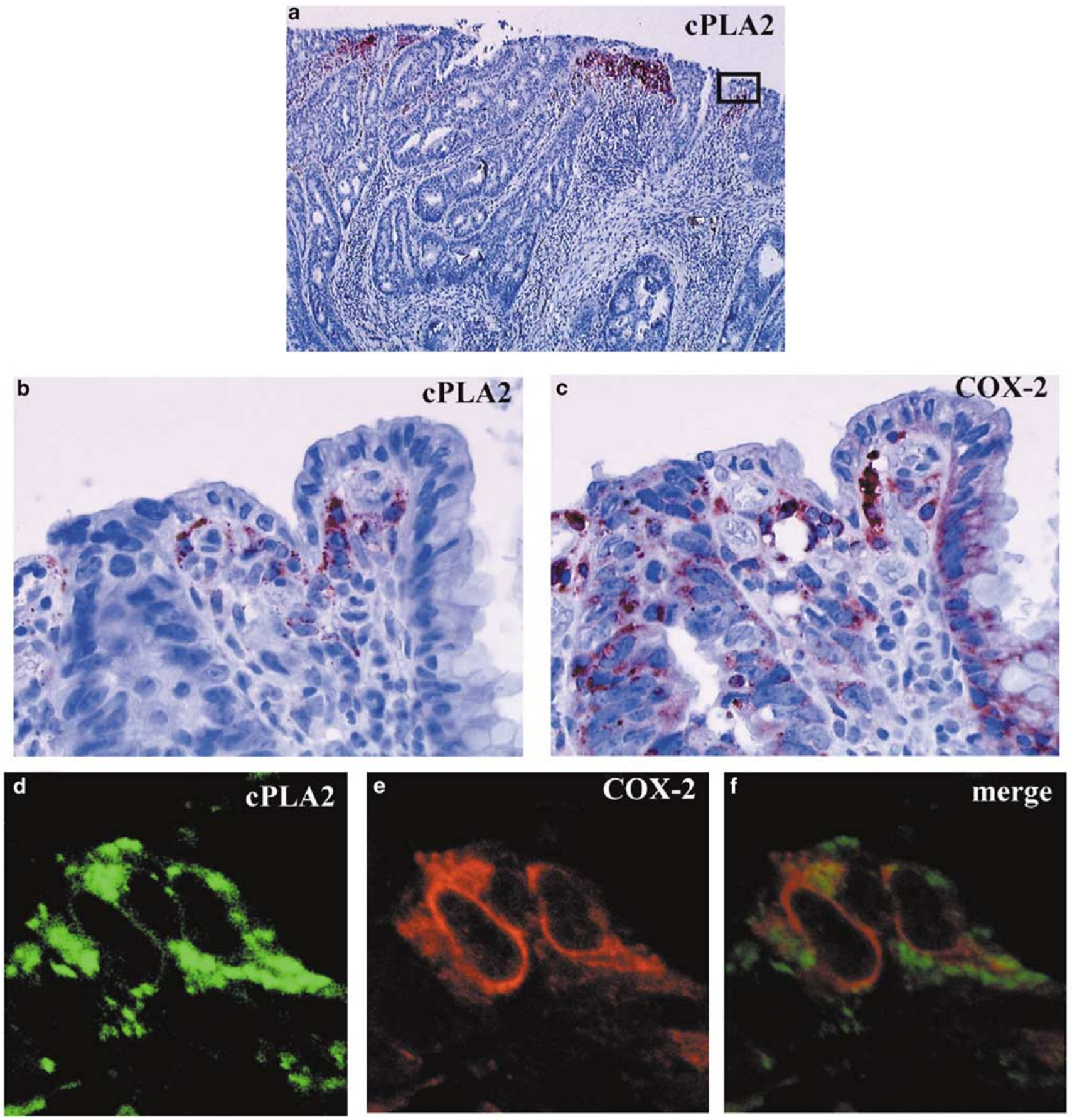

Figure 1 (a-c) Immunohistochemical staining of cytoplasmic PLA2 (a, b) and COX-2 in a human colon carcinoma. (a) low magnification $(\times 50)$ showing cytoplasmic PLA2-positive stromal cells situated just below the surface epithelium, $(\mathbf{b}, \mathbf{c})$ high magnification $(\times 400)$ of the box area showing, (b) A cytoplasmic and granular staining of cytoplasmic PLA2 in superficial stromal cells and (c) a cytoplasmic immunostaining of COX-2 in superficial stromal cells and in tumor cells (hematoxylin counterstaining). (d-f) Immunofluorescent labeling of cytoplasmic PLA2 (d) and COX-2 (e) in superficial stromal cells analyzed by confocal microscopy. (d) Patchy cytoplasmic and moderate perinuclear localization of cytoplasmic PLA2 in superficial stromal cells, (e) cytoplasmic and perinuclear localization of COX-2 in the same cells and (f) merged image of cytoplasmic PLA2 and COX-2 immunofluorescent labeling.

A high number of superficial stromal cells expressing cytoplasmic PLA2 was correlated with a strong VEGF expression $(P=0.01)$ (Figure 2a) and a high microvessel density $(P=0.002)$ (Figure $2 b)$. A lower number of cytoplasmic PLA2-positive stromal cells was seen in colon carcinomas with microsatellite instability when compared to carcinomas without microsatellite instability $(P=0.001$, 
Table 1 Median number and interquartile range of cytoplasmic PLA2-positive stromal cells, COX-2-positive stromal cells and intratumoral microvessel density in colorectal carcinomas expressed as the number of cells or vessels $/ \mathrm{mm}^{2}$

\begin{tabular}{lccc}
\hline & All carcinomas & $\begin{array}{c}\text { Carcinomas without } \\
\text { microsatellite instability }\end{array}$ & $\begin{array}{c}\text { Carcinomas with } \\
\text { microsatellite instability }\end{array}$ \\
\hline cPLA2-expressing stromal cells & $62.8(15.4-114.8)$ & $84.6(30.1-184.2)$ & $26.9(0-67.3)$ \\
COX-2-expressing stromal cells & $212.8(116.0-283.3)$ & $242.3(123.7-298.0)$ & $179.5(73.1-212.2)$ \\
Intratumoral microvessel density & $93.3(73.2-108.2)$ & $99.0(88.4-111.6)$ & $73.2(58.5-87.1)$ \\
\hline
\end{tabular}

Table 1). There was no association between the number of cytoplasmic PLA2-positive superficial stromal cells and stage of the carcinomas $(P=0.35)$.

Double immunofluorescent staining with confocal microscopy showed that cytoplasmic PLA2 protein was mainly situated in the cytoplasm with a patchy distribution, but also in the perinuclear region although with a lesser intensity (Figure 1d). In the five studied samples, superficial stromal cells expressing cytoplasmic PLA2 also expressed COX2 (Figure 1f). Cytoplasmic PLA2-positive stromal cells did not express CD68 (macrophage marker) (Figure 3a-c). Cytoplasmic PLA2-positive stromal cells expressed vimentin (Figure $3 \mathrm{~d}-\mathrm{f}$ ) and sometimes smooth muscle actin (myofibroblast marker) (Figure 3g-i).

\section{COX-2 Expressing Stromal Cells}

COX-2 immunostaining in superficial stromal cells appeared cytoplasmic (Figure 1c). The median number of COX-2-positive superficial stromal cells in colon carcinomas was $212.8 / \mathrm{mm}^{2}$ (Table 1). There was neither association between the number of COX-2-positive superficial stromal cells and VEGF expression and microvessel density $(P=0.29$ and 0.81 , respectively). There were less numerous COX2-positive superficial stromal cells in tumors with microsatellite instability $(P=0.03$, Table 1$)$.

There was no association between the number of COX-2-positive superficial stromal cells and the stage of the carcinomas $(P=0.13)$.

Confocal microscopy showed that COX-2 protein was situated in the cytoplasm and around the nuclei in the superficial stromal cells (Figure 1e).

\section{VEGF Expression and Intratumoral Microvessel Density}

The median number of intratumoral vessels in colon carcinomas was $93.3 / \mathrm{mm}^{2}$ (Table 1). There was a positive correlation between VEGF expression and microvessel density $\left(P<10^{-5}\right)$. Colorectal carcinomas with microsatellite instability had a lower microvessel density and VEGF expression compared to colorectal carcinomas without microsatellite instability $(P=0.0007$ and 0.04 , respectively).

\section{Discussion}

Cytoplasmic PLA2 has been shown to be overexpressed in colon carcinoma in some studies; however, most of these studies did not define which cells overexpressed cytoplasmic PLA2, as they did not use in situ techniques. ${ }^{29-31}$ In the studies that used immunohistochemistry, some authors demonstrate a diminished cytoplasmic PLA2 staining in the tumor cells compared to normal epithelium. ${ }^{32}$ Others report an overexpression of cytoplasmic PLA2 in tumor cells in up to $35 \%$ of the colorectal cancers but this overexpression is then most often weak or moderate. ${ }^{19,33}$ So far, no study focused on cytoplasmic PLA2 expression in stromal cells in colorectal carcinomas. We show a high protein expression of cytoplasmic PLA2 in superficial stromal cells in colorectal carcinomas. These cells are exclusively situated in the superficial stroma, just below the surface epithelium and we identified these cells as fibroblasts and myofibroblasts. After immunofluorescent labeling and confocal microscopy analysis, the intracellular distribution of cytoplasmic PLA2 appears cytoplasmic and patchy with a moderate perinuclear distribution. This pattern has already been described in several studies and may correspond to a colocalization with cytoplasmic lipid bodies. ${ }^{34,35}$ Cytoplasmic PLA2 overexpression in these cells is often associated with COX-2 expression. Indeed, our immunohistochemical results showed a statistical relation between the number of cytoplasmic PLA2- and COX-2positive stromal cells $(P=0.006)$. However, in most cases there were less numerous cytoplasmic PLA2positive stromal cells than COX-2-positive stromal cells. Moreover, by confocal microscopy we show a coexpression of these two enzymes in the superficial stromal cells: most of the cytoplasmic PLA2-expressing stromal cells also expressed COX-2. In accordance with this finding, COX-2 expression has already been demonstrated in interstitial cells of human colon adenomas and carcinomas. ${ }^{12,14,36}$ Some authors found that COX-2-positive interstitial cells correspond mainly to macrophages ${ }^{10-12}$ but others demonstrate COX-2 expression mainly in fibroblasts. ${ }^{13,14}$ Our results indicate that superficial fibroblasts and myofibroblasts may express cytoplasmic PLA2 as well as COX-2 and are thus in accordance with these latter studies. In these 

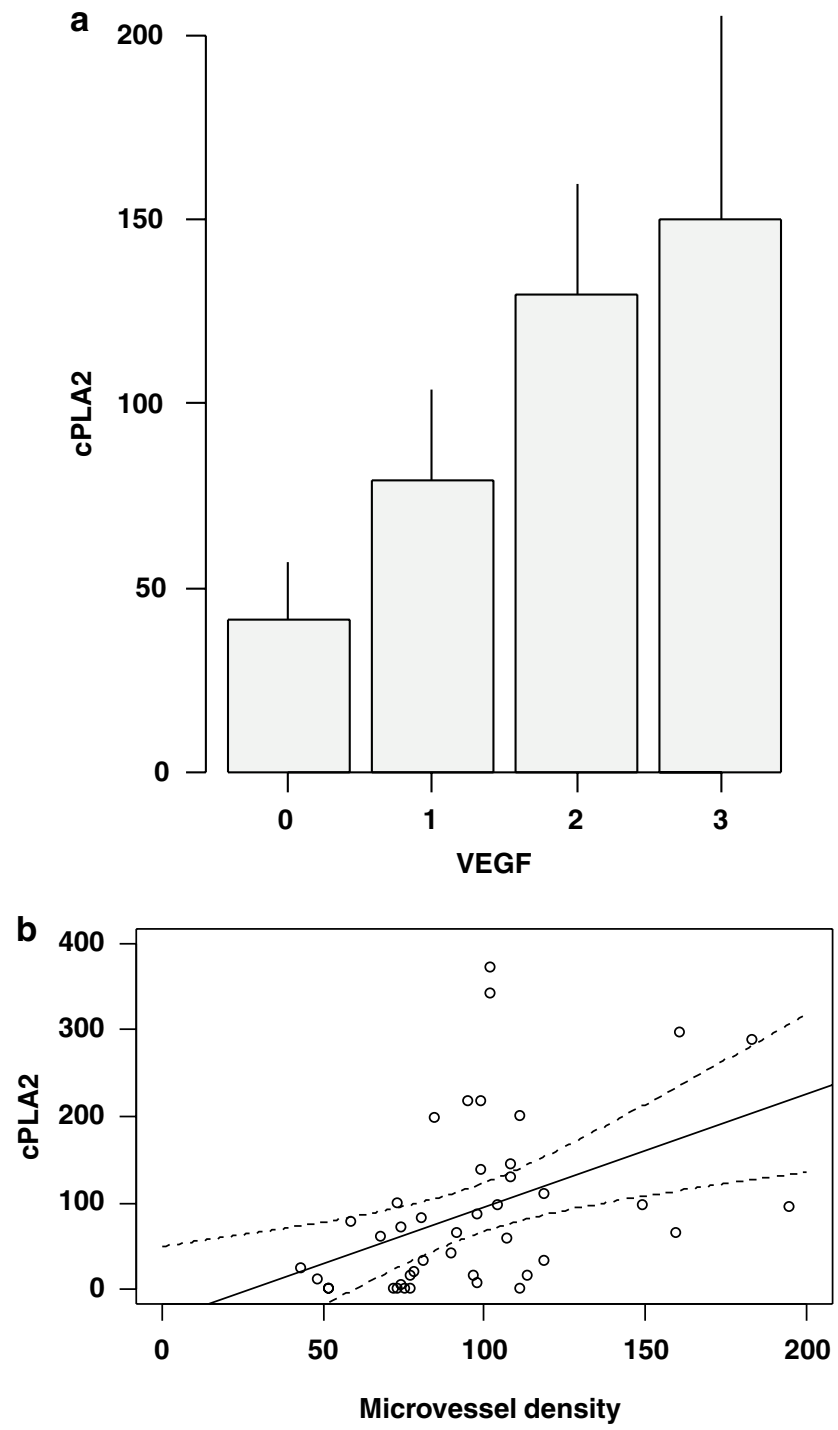

Figure 2 Correlation between the number of cytoplasmic PLA2expressing superficial stromal cells and (a) VEGF expression in tumor cells $(P=0.009)$ and $(b)$ intratumoral microvessel density $(P=0.002)$. (a) Number of cytoplasmic PLA2-positive stromal cells according to VEGF. Bars indicate the mean number of cytoplasmic PLA2-positive stromal cells $\left(/ \mathrm{mm}^{2}\right)$ and lines correspond to the standard error of the mean in each group. VEGF staining in tumor cells is scored semiquantitatively from 0 to 3. Cytoplasmic PLA2-expressing superficial stromal cells were counted in four random $\times 400$ fields. Their number is expressed/ $\mathrm{mm}^{2}$. For tumors with the same VEGF score, the mean number of cytoplasmic PLA2-expressing superficial stromal cells and the standard error are represented. (b) Number of cytoplasmic PLA2positive stromal cells according to microvessel density. The plain line corresponds to the linear regression with $95 \%$ confidence interval dotted. The total number of cytoplasmic PLA2-expressing superficial stromal cells counted in four random $\times 400$ fields is expressed $/ \mathrm{mm}^{2}$ and represented in each case. Microvessel density was evaluated in ten consecutive fields $\times 400$ after CD31 immunostaining and is expressed as the total number of microvessels $/ \mathrm{mm}^{2}$.

superficial stromal cells, COX-2 was situated in the cytoplasm and the perinuclear region in accordance with the endoplasmic reticulum and perinuclear membrane localization of COX $-2 .^{37}$
Overexpression of both cytoplasmic PLA2 and COX-2 in stromal cells could lead to high levels of prostaglandin production because a coordinate activation of PLA2 and COX-2 is necessary to produce significant amounts of prostaglandins. ${ }^{38}$ Although, an increased protein expression does not necessarily indicate an important activation or increased function, the moderate perinuclear cPLA2 distribution seen by confocal microscopy could be related to cytoplasmic PLA2 activation. ${ }^{39}$

Since our approach is based on immunohistochemistry and image analysis in human lesions, we could not directly demonstrate a high cytoplasmic PLA2 activity or high prostaglandin production. We thus wanted to determine if cytoplasmic PLA2 protein overexpression in stromal cells could be linked with a biological effect known to be regulated in colorectal cancer by COX-2-induced prostaglandin production. In particular, we investigated a possible relation between the number of cytoplasmic PLA2-expressing stromal cells and tumor angiogenesis. Indeed, previous studies in mice have shown that COX-2 overexpression in stromal cells is associated with tumor angiogenesis. ${ }^{15}$ In particular, it has been shown that COX-2 expression in stromal cells results in high prostaglandin E2 levels, which induce VEGF expression and angiogenesis. ${ }^{16,17}$ In our study, we found no association between the number of COX-2 expressing superficial stromal cells and microvessel density or VEGF expression $(P=0.81$ and 0.29 , respectively) in colorectal carcinomas. Although a relation between COX-2 expressing stromal cells and angiogenesis was found by Chapple et $a l^{40}$ in colorectal adenomas, no study reported such a relation in human colorectal carcinomas. This could be linked to tumor progression. On the contrary, we found a strong association between the number of cytoplasmic PLA2-positive stromal cells and microvessel density and VEGF expression $(P=0.002$ and 0.01 , respectively). As cytoplasmic PLA2 specifically hydrolyses arachidonic acid from membrane phospholipids, which is the limiting factor for prostaglandin production, ${ }^{41}$ our results could suggest that, in colorectal carcinomas, cytoplasmic PLA2 overexpression in stromal cells regulates COX-induced angiogenesis probably by providing arachidonic acid.

We also studied the relation between cytoplasmic PLA2, COX-2-expressing superficial stromal cells and microsatellite instability. Indeed, it has been shown that microsatellite instability in colorectal cancer is associated with a lower microvessel density and VEGF expression. ${ }^{21,22}$ In accordance with these previous results, we found a lower microvessel density and VEGF expression in tumors with microsatellite instability $(P=0.0007$ and 0.04 , respectively). We also found less cytoplasmic PLA2 and less COX-2-positive stromal cells in tumors with microsatellite instability compared to tumors without microsatellite instability $(P=0.001$ and 0.03 , respectively). As we showed a relation 

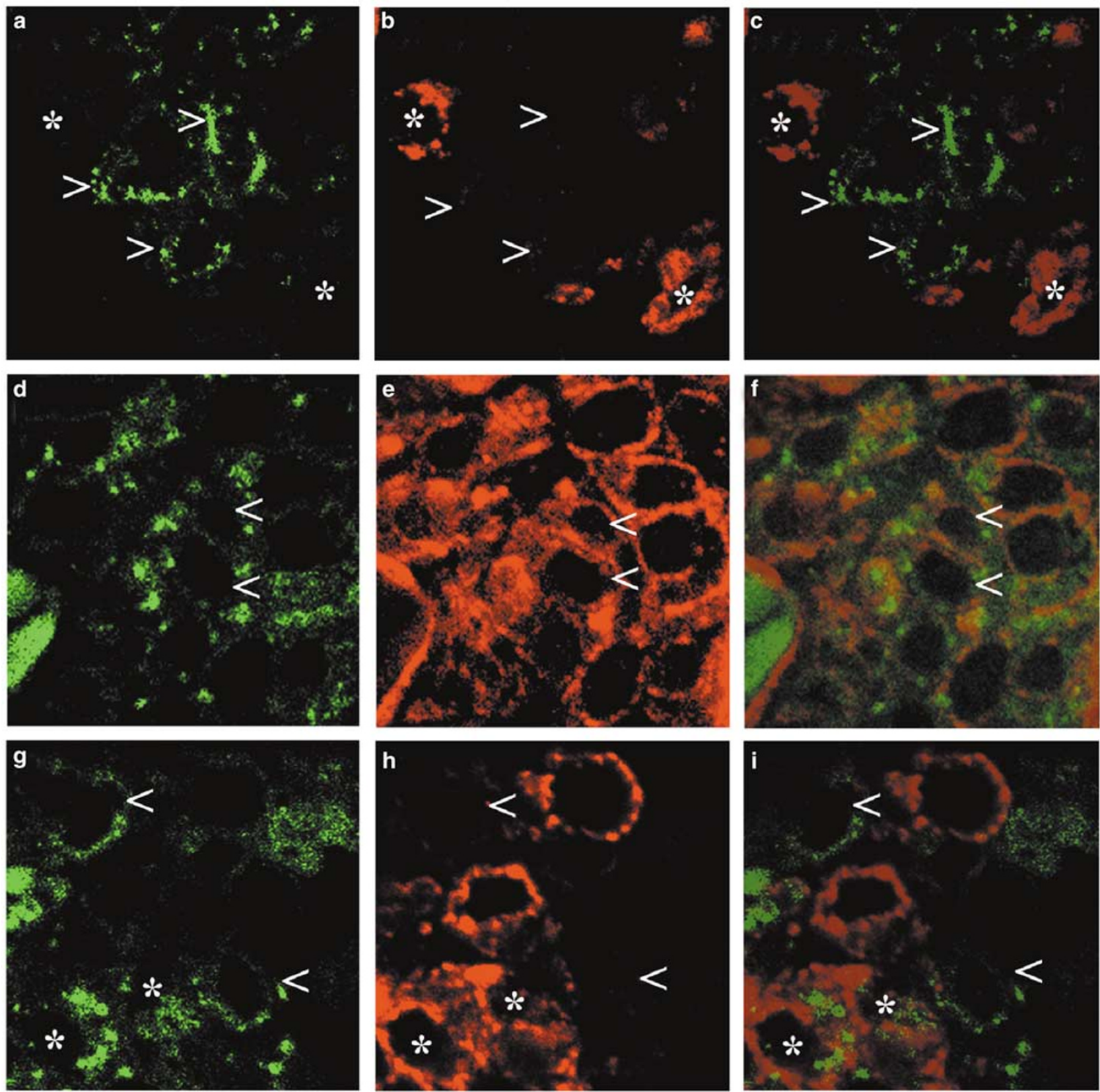

Figure 3 (a-c) Immunostaining for cytoplasmic PLA2 (a) and CD68 (b) and the merged image (c) Showing no CD68 expression in cytoplasmic PLA2-positive cells (arrows). Stars indicate CD68 positive cells that do not stain for cytoplasmic PLA2. (d-f) Immunostaining for cytoplasmic PLA2 (d) and vimentin (e) and the merged image (f) showing cytoplasmic PLA2 and vimentin expression in the same cells (arrows). (g-i) Immunostaining for cytoplasmic PLA2 (g) and smooth muscle actin (h) and the merged image (i) showing some cytoplasmic PLA2-positive cells also positive for smooth muscle actin (stars). Some cytoplasmic PLA2-positive cells are negative for smooth muscle actin (arrows).

between cytoplasmic PLA2-positive superficial stromal cells and angiogenesis, the lower number of cytoplasmic PLA2-positive superficial stromal cells in tumors with microsatellite instability could explain their lower microvessel density and VEGF expression. The link between microsatellite instability and COX-2 or cytoplasmic PLA2 expression is yet unknown. Some genetic alterations in colorectal carcinomas such as Wnt and Ras pathway activation were shown to regulate COX-2 and cytoplasmic PLA2 expression in tumor cells ${ }^{42,43}$ and could be implicated since stromal cells may also have genetic alterations. ${ }^{4}$

In summary, we demonstrated the presence of cytoplasmic PLA2 overexpressing superficial stromal cells in colorectal carcinomas. These cells correspond to fibroblasts and myofibroblasts. They usually also express COX-2. Moreover, we found an 
association between a high number of cytoplasmic PLA2-positive stromal cells, a high microvessel density, a strong VEGF expression and the absence of microsatellite instability. On the contrary we found no association between the presence of COX2-positive superficial stromal, microvessel density VEGF expression. Although these correlations based on in situ analysis of human tissues do not demonstrate a precise mechanism, they are coherent with most of the studies and knowledge concerning COX-2 and prostaglandin roles in colorectal tumor development. It is most likely that the coordinate overexpression of cytoplasmic PLA2 and COX-2 in stromal cells could lead to an important prostaglandin production. In addition, cytoplasmic PLA2 overexpression in these cells could regulate COX-induced angiogenesis probably by providing arachidonic acid that is the limiting factor for prostaglandin production. The lower number of cytoplasmic PLA2-positive stromal cells in carcinomas with microsatellite instability could also explain their lower microvessel density and VEGF expression.

\section{Acknowledgements}

We are grateful to Nicole Sebbagh and Philippe Fontanges for their technical help and skills.

\section{References}

1 Liu CH, Chang SH, Narko K, et al. Overexpression of cyclooxygenase-2 is sufficient to induce tumorigenesis in transgenic mice. J Biol Chem 2001;276: 18563-18569.

2 Oshima M, Dinchuk JE, Kargman SL, et al. Suppression of intestinal polyposis in Apc delta716 knockout mice by inhibition of cyclooxygenase 2 (COX-2). Cell 1996;87:803-809.

3 Jacoby RF, Seibert K, Cole CE, et al. The cyclooxygenase-2 inhibitor celecoxib is a potent preventive and therapeutic agent in the min mouse model of adenomatous polyposis. Cancer Res 2000;60:5040-5044.

4 Chulada PC, Thompson MB, Mahler JF, et al. Genetic disruption of Ptgs-1, as well as Ptgs-2, reduces intestinal tumorigenesis in Min mice. Cancer Res 2000;60:4705-4708.

5 Oshima M, Murai N, Kargman S, et al. Chemoprevention of intestinal polyposis in the Apcdelta716 mouse by rofecoxib, a specific cyclooxygenase- 2 inhibitor. Cancer Res 2001;61:1733-1740.

6 Gupta RA, Dubois RN. Colorectal cancer prevention and treatment by inhibition of cyclooxygenase-2. Nat Rev Cancer 2001;1:11-21.

7 Tsujii M, Kawano S, Tsuji S, et al. Cyclooxygenase regulates angiogenesis induced by colon cancer cells. Cell 1998;93:705-716.

8 Masunaga R, Kohno H, Dhar DK, et al. Cyclooxygenase-2 expression correlates with tumor neovascularization and prognosis in human colorectal carcinoma patients. Clin Cancer Res 2000;6:4064-4068.

9 Cianchi F, Cortesini C, Bechi P, et al. Up-regulation of cyclooxygenase 2 gene expression correlates with tumor angiogenesis in human colorectal cancer. Gastroenterology 2001;121:1339-1347.

10 Hull MA, Booth JK, Tisbury A, et al. Cyclooxygenase 2 is up-regulated and localized to macrophages in the intestine of Min mice. Br J Cancer 1999;79:1399-1405.

11 Bamba H, Ota S, Kato A, et al. High expression of cyclooxygenase-2 in macrophages of human colonic adenoma. Int J Cancer 1999;83:470-475.

12 Chapple KS, Cartwright EJ, Hawcroft G, et al. Localization of cyclooxygenase-2 in human sporadic colorectal adenomas. Am J Pathol 2000;156:545-553.

13 Shattuck-Brandt RL, Varilek GW, Radhika A, et al. Cyclooxygenase 2 expression is increased in the stroma of colon carcinomas from IL-10(-/-) mice. Gastroenterology 2000;118:337-345.

14 Sonoshita M, Takaku K, Oshima M, et al. Cyclooxygenase-2 expression in fibroblasts and endothelial cells of intestinal polyps. Cancer Res 2002;62: 6846-6849.

15 Williams CS, Tsujii M, Reese J, et al. Host cyclooxygenase-2 modulates carcinoma growth. J Clin Invest 2000;105:1589-1594.

16 Sonoshita M, Takaku K, Sasaki N, et al. Acceleration of intestinal polyposis through prostaglandin receptor EP2 in Apc(Delta 716) knockout mice. Nat Med 2001;7:1048-1051.

17 Seno H, Oshima M, Ishikawa TO, et al. Cyclooxygenase 2- and prostaglandin E(2) receptor EP(2)-dependent angiogenesis in Apc(Delta716) mouse intestinal polyps. Cancer Res 2002;62:506-511.

18 Six DA, Dennis EA. The expanding superfamily of phospholipase A(2) enzymes: classification and characterization. Biochim Biophys Acta 2000;1488:1-19.

19 Wendum D, Svrcek M, Rigau V, et al. COX-2, inflammatory secreted PLA2, and cytoplasmic PLA2 protein expression in small bowel adenocarcinomas compared with colorectal adenocarcinomas. Mod Pathol 2003;16:130-136.

20 Karnes Jr WE, Shattuck-Brandt R, Burgart LJ, et al. Reduced COX-2 protein in colorectal cancer with defective mismatch repair. Cancer Res 1998;58: 5473-5477.

21 Wynter CV, Simms LA, Buttenshaw RL, et al. Angiogenic factor VEGF is decreased in human colorectal neoplasms showing DNA microsatellite instability. J Pathol 1999;189:319-325.

22 Wendum D, Boelle PY, Rigau V, et al. Mucinous colon carcinomas with microsatellite instability have a lower microvessel density and lower vascular endothelial growth factor expression. Virchows Arch 2003;442: 111-117.

23 Sinicrope FA, Lemoine M, Xi L, et al. Reduced expression of cyclooxygenase 2 proteins in hereditary nonpolyposis colorectal cancers relative to sporadic cancers. Gastroenterology 1999;117:350-358.

24 Rigau V, Sebbagh N, Olschwang S, et al. Microsatellite instability in colorectal carcinoma. The comparison of immunohistochemistry and molecular biology suggests a role for hMSH6 immunostaining. Arch Pathol Lab Med 2003;127:694-700.

25 Sobin LH, Wittekind C, (eds). TNM Classification of Malignant Tumors, 5th edn. Wiley-Liss: New York, 1997.

26 Boland CR, Thibodeau SN, Hamilton SR, et al. A National Cancer Institute Workshop on Microsatellite Instability for cancer detection and familial predisposition: development of international criteria 
for the determination of microsatellite instability in colorectal cancer. Cancer Res 1998;58: 5248-5257.

27 Marcus VA, Madlensky L, Gryfe R, et al. Immunohistochemistry for hMLH1 and hMSH2: a practical test for DNA mismatch repair-deficient tumors. Am J Surg Pathol 1999;23:1248-1255.

28 Couvelard A, Paraf F, Gratio V, et al. Angiogenesis in the neoplastic sequence of Barrett's oesophagus. Correlation with VEGF expression. J Pathol 2000;192: 14-18.

29 Soydan AS, Tavares IA, Weech PK, et al. High molecular weight phospholipase A2 and fatty acids in human colon tumours and associated normal tissue. Eur J Cancer 1996;32A:1781-1787.

30 Dimberg J, Samuelsson A, Hugander A, et al. Gene expression of cyclooxygenase-2, group II and cytosolic phospholipase A2 in human colorectal cancer. Anticancer Res 1998;18:3283-3287.

31 Osterstrom A, Dimberg J, Fransen K, et al. Expression of cytosolic and group X secretory phospholipase A(2) genes in human colorectal adenocarcinomas. Cancer Lett 2002;182:175-182.

32 Dong M, Guda K, Nambiar PR, et al. Inverse association between phospholipase A2 and COX-2 expression during mouse colon tumorigenesis. Carcinogenesis 2003;24:307-315.

33 Morioka Y, Ikeda M, Saiga A, et al. Potential role of group $\mathrm{X}$ secretory phospholipase $\mathrm{A}(2)$ in cyclooxygenase-2-dependent PGE(2) formation during colon tumorigenesis. FEBS Lett 2000;487:262-266.

34 Bunt G, de Wit J, van den Bosch $\mathrm{H}$, et al. Ultrastructural localization of cPLA2 in unstimulated and EGF/A23187-stimulated fibroblasts. J Cell Sci 1997; 110:2449-2459.

35 Yu W, Bozza PT, Tzizik DM, et al. Co-compartmentalization of MAP kinases and cytosolic phospholipase
A2 at cytoplasmic arachidonate-rich lipid bodies. Am J Pathol 1998;152:759-769.

36 Sano H, Kawahito Y, Wilder RL, et al. Expression of cyclooxygenase-1 and -2 in human colorectal cancer. Cancer Res 1995;55:3785-3789.

37 Spencer AG, Woods JW, Arakawa T, et al. Subcellular localization of prostaglandin endoperoxide $\mathrm{H}$ synthases-1 and -2 by immunoelectron microscopy. J Biol Chem 1998;273:9886-9893.

38 Balsinde J, Balboa MA, Dennis EA. Functional coupling between secretory phospholipase A2 and cyclooxygenase-2 and its regulation by cytosolic group IV phospholipase A2. Proc Natl Acad Sci USA 1998;95: 7951-7956.

39 Glover S, de Carvalho MS, Bayburt T, et al. Translocation of the $85-\mathrm{kDa}$ phospholipase A2 from cytosol to the nuclear envelope in rat basophilic leukemia cells stimulated with calcium ionophore or IgE/antigen. J Biol Chem 1995;270:15359-15367.

40 Chapple KS, Scott N, Guillou PJ, et al. Interstitial cell cyclooxygenase-2 expression is associated with increased angiogenesis in human sporadic colorectal adenomas. J Pathol 2002;198:435-441.

41 Balsinde J, Balboa MA, Insel PA, et al. Regulation and inhibition of phospholipase A2. Annu Rev Pharmacol Toxicol 1999;39:175-189.

42 Araki Y, Okamura S, Hussain SP, et al. Regulation of cyclooxygenase-2 expression by the Wnt and ras pathways. Cancer Res 2003;63:728-734.

43 Heasley LE, Thaler S, Nicks M, et al. Induction of cytosolic phospholipase A2 by oncogenic Ras in human non-small cell lung cancer. J Biol Chem 1997;272:14501-14504.

44 Wernert N, Locherbach C, Wellmann A, et al. Presence of genetic alterations in microdissected stroma of human colon and breast cancers. Anticancer Res 2001;21:2259-2264. 